\title{
LXII. The fatigue of metals subjected to Röntgen radiation
}

\section{Louis T. More Ph.D.}

To cite this article: Louis T. More Ph.D. (1907) LXII. The fatigue of metals subjected to Röntgen radiation, Philosophical Magazine Series 6, 13:78, 708-721, DOI: 10.1080/14786440709463649

To link to this article: http://dx.doi.org/10.1080/14786440709463649

曲 Published online: 16 Apr 2009.

Submit your article to this journal ¿

Џ Article views: 4

Q View related articles $\square$

Citing articles: 2 View citing articles 5 
capacity being thereby introduced. It appears, in fact, that for assemblages of electrons to be able to give rise to a dielectric capacity different from that of free æther, the constitution of the electron must be assumed to involve electric displacement so great that electric displacement and electric force are no longer linearly related. It is not to be supposed that this would involve (for example) non-linearity of the equations of optics: in radiation traversing free æother, as already explained, we are dealing with values of electric displacement which could still be well within the limits of sensibly linear relation; while the optical phenomena exhibited by (say) ordinary transparent media would fall within the category of small oscillations about a configuration of equilibrium, or about a state of quasi-steady motion, and would accordingly be deducible from linear equations. In this connexion it is not even necessary to take account of the circumstance that each individual electron, notwithstanding the non-linear strain-relations involved in its constitution, would obey (for moderate velocities) very simple laws of motion. As a rough general analogy it may be helpful to consider a thin spring laterally loaded to such an extent that the relation between the load and the resulting deformation is not even approximately linear. None the less the small oscillations of such a system about a position of equilibrium will be isochronous, and deducible from a system of linear equations.

22. Some progress has recently been made towards a static conception of atomic structure, and in relation to such theories especial significance attaches to questions regarding the possible non-linearity of electro-magnetic relations, with corresponding modification of the law of force between electrons placed in elose proximity to one another.

LXII. The Fatigue of Metals subjected to Röntgen Radiation. By Louis T. More, Ph.D., Professor of Physics in the University of Cincinnati*.

GINCE the discovery of Hallwachs that metals grow less $N$ sensitive to ultra-violet light after long exposure to the rays, many attempts have been made to determine the cause and laws of this "photo-electric fatigue." Some discrepancies in the results still exist, but there is general agreement that it varies with the kind of metal used, the state of the surface, the gas in which the metal is placed, and the character of the rays. We know so little about the nature

- Communicated by the Author. 
of a metallic surface and of the condition of adherent gaseous layers, that it is natural to expect discrepancies where these are controlling factors.

As a summary of the work is given in Professor Thomson's 'Conduction of Electricity through Gases,' page 289, it is necessary only to supplement this by reference to what has appeared since. Ramsay and Spencer* have attempted to prove that this fatigue is conditioned by the disintegration of the metallic atoms. Allen $\dagger$ has solved one difficulty by proving that fatigue occurs in a good vacuum, and has added the new and important fact that the fatigue of zinc can be expressed as a sum of two exponential terms. He also shows that the longer waves possess the property of producing a partial recovery in the activity, the exponential decay having been obtainable only when they were absorbed. It is to be hoped he will continue the work to include the details of this important property. In addition to this new matter, Hallwachs $\ddagger$ has continued his researches and published them in an elaborate and comprehensive paper. In the first part he considers the various hypotheses in detail, and apparently on good evidence rejects the conclusions of Ladenburg $\S$ that the fatigue is caused by oxidation or corrosion of the metal, and proves, contrary to Buisson $\|$ and Kreusler $\Psi_{i}$, that darkness does not prevent fatigue. In the second part of the paper he investigates the cause of the effect. Here he confirms the theories of Lenard ${ }^{* *}$ and Buisson, that the fatigue is due in part to absorption of the radiation from the metal by electrified double-layers and films of gas on the surface, modified in some way by the ultra-violet light. But he assigns the dominant influence to the presence of ozone in these absorption-layers. However, it has yet to be proved that minute quantities of ozone possess such an abnormally large absorptive power on the cathode rays issuing from the metal. He also shows that the activity may increase to a maximum value before fatigue begins.

As Röntgen rays excite a secondary radiation in metals we may expect to find, in this case, effects of fatigue; and the experiments described in this paper prove that this type

* Ramsay and Spencer, Phil. Mag. xii. 1906, p. 397.

† H. S. Allen, Proc. Roy. Suc. A, Ixxviii. 1907, p. 483.

$\ddagger$ Hallwachs, Sitzungsber. der Ges. der Wissensch. za Leipzig, Iviii. 1906, p. 341 .

5 Ladenburg, Annal. der Phys. xii. 1903, p. 558.

II Buisson, Ann. de Chim. et de Phys. xxiv. 1901, p. 320.

If Kreusler, Annal. der Phys. vi. 1901, p. 398.

* Lenard, Annal. der Phys. viii. 1902, p. 196 ; xii. 1903, p. 490. 
of secondary radiation is variable; the changes, however, differ in many respects from the photo-electric effect.

Until we can devise a method of obtaining a constant source of Röntgen radiation, we are limited to a choice of comparative measurements. Another complication which makes accuracy difficult, is the impossibility of making an induction-coil work steadily for the length of time employed in photo-electric work. So the attempt was made to measure such small effects as might take place during a few hours of exposure. The method adopted to eliminate irregularities of coil and bulb was a comparative one. The secondary radiation excited by the Röntgen rays in two similar plates was measured. One of them, which I shall call the standard plate, was then screened from the rays that continued to fall upon the other, or trial plate. At intervals afterwards the secondary radiation from both plates was observed. Variations in the ratios of the radiation from the fresh plate and the other exposed continuously to the rays, are a relative measure of the effect of the Röntgen rays on the trial plate. To have values accurate as well as characteristic, a coil was chosen which worked with steadiness, and the bulb was provided with a regulator which, with gentle heating, kept the rays soft and as uniform as possible.

Fig. 1.

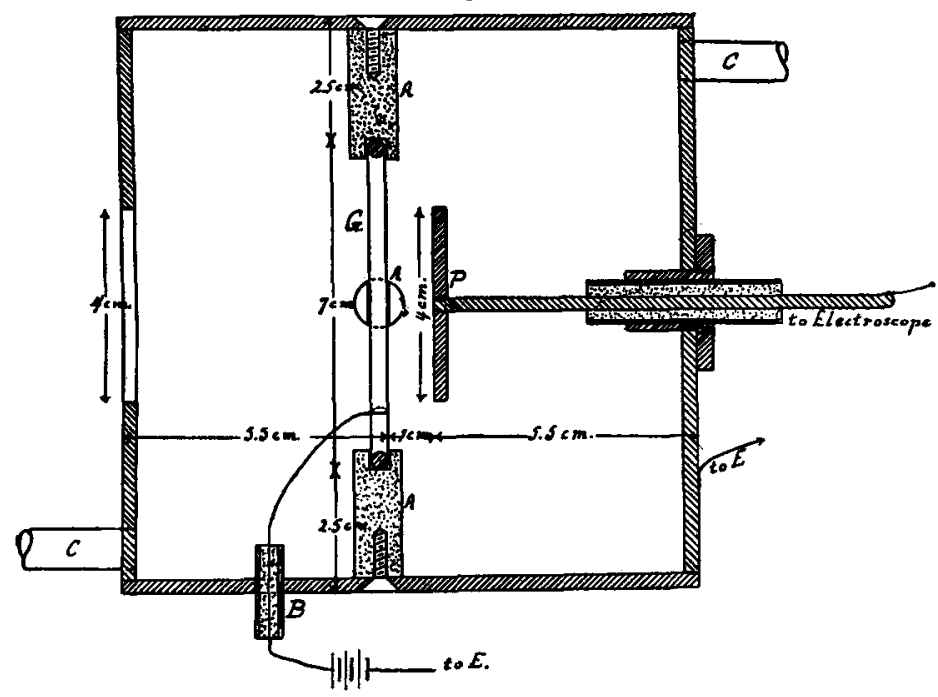

The apparatus adopted is shown in fig. 1. Two exactly similar brass boxes, $12 \mathrm{cms}$. in each direction, served as 
ionization-chambers. The Röntgen rays entered each box by a circular window in the front face and, after passing through a disk of iron-wire gauze, impinged on a circular disk of the metal to be tested. The gauze disk, G, soldered to an iron ring, was held in place by three slotted pillars of ebonite, A. Wires, which entered the boxes through sulphur insulators, connected the gauze disks to the positive pole of the same battery of a hundred cells. The metal plate, P, placed a centimetre behind the gauze disk, was joined to a Wilson gold-leaf inclined electroscope by a rod which was insulated from the box by a sulphur plug. 'The tubes, C, served to admit various gases, and when air was not used, thin sheets of aluminium closed the windows in the boxes.

These boxes were mounted (fig. 2) so that horizontal and

Fig. 2.

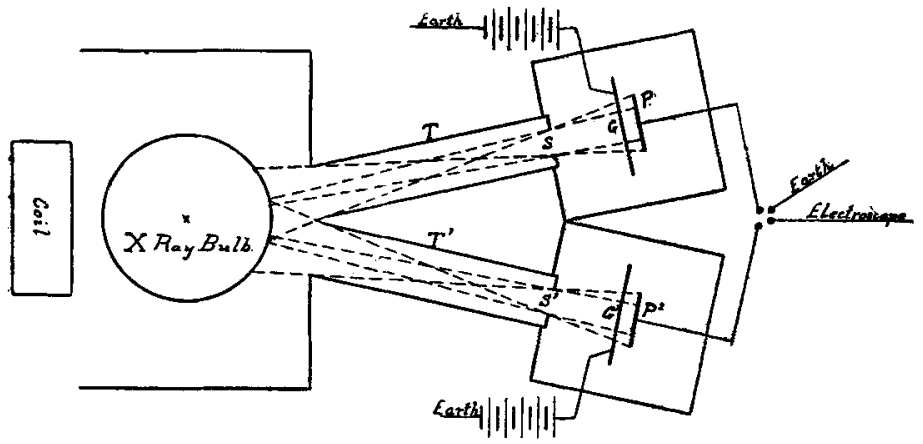

approximately equal beams from a Röntgen-ray bulb, X, entered their windows. Spring-lever keys operated by cords were arranged to connect the experimental plates, $\mathrm{P}$ and $\mathrm{P}^{\prime}$, separately to the gold-leaf of the electroscope, to earth, or together. To measure the ionization-currents created by the secondary radiation between the condenser-plates, the electroscope was charged to 200 volts and was tilted at an angle to give a motion of the leaf of about forty divisions in the microscope-micrometer in half a minute.

As is usual, the bulb and coil were screened by a leadsheathed box and all electrical connexions were encased in metal tubes, connected to earth. At $\mathbf{S}$ and $\mathbf{S}^{\prime}$, in front of the windows, lead shutters were hung, which could be raised or lowered by cords. When closed no appreciable ionization was produced in the boxes.

In the earlier part of the work, the rays were allowed to fall not only on the experimental plates but also on a guardring or the inner surfaces of the box. But it was found that 
the secondary radiation excited in these latter caused serious errors. To eliminate them, the brass tubes ' $\mathrm{T}, \mathrm{T}$ ' were mounted in such a fashion as to stop all rays but those which struck the experimental plates.

The following preliminary steps show the reliability of the arrangements :-

1. When the electroscope was disconnected from the plates, rays from the bulb, within or outside the boxes, caused no appreciable motion of the leaf during a minute.

2. With the lead shutters closed and the electroscope connected to the plates, the rays produced no observable ionization in the boxes.

3. Since the Röntgen rays passed through the wire gauze and the air-space between it and the metal plate, a test was made to determine the secondary radiation from the gauze. First, the ratio of the ionization-currents in the two boxes was measured, using lead plates and iron gauze in both. One of these gauze disks was then replaced by a similar one of copper, and the ratio again found. As the two ratios remained the same, the action of the rays on the gauze can be neglected. As an additional proof, the ionization-current was measured, using a lead plate; this was then replaced by a disk of the same size made of very thin aluminium-foil mounted on a fine brass wire. The two observations showed that only about one per cent. of the first ionization remained, and as that was parlly due to secondary radiation from the aluminiumfoil, the direct ionization of the Röntgen rays and that due to the secondary radiation of the gauze must be less than one per cent. and so negligible.

The effect of the Röntgen rays was tried on iron, lead, nickel, zine, copper, and aluminium, both with old and with polished surfaces in air. And, in addition to air, the gases hydrogen, coal-gas, and ozone were used. The results show that the secondary radiation excited by these rays depends on the length of exposure, the kind of metal, its surface, and the gas surrounding it; but the changes differ in many respects from the effects produced by ultra-violet light.

In the tables the column "Exposure" shows the period the trial plate was exposed continuously to the rays; the column for each metal gives the ratio of the ionization-current from the trial plate to that of the standard. In each case the initial reading of this ratio is expressed as 100 ; the per-cent. change in the amount of the secondary radiation from the trial plate can thus be found at once by subtracting any subsequent value from the initial reading. The ionization- 
current was determined by noting with a stop-watch the time which the gold-leaf of the electroscope required to move over a given number of divisions of the microscope-micrometer. The reciprocal of this time is a measure of the current produced by the secondary radiation of the metal. Alternative readings were made with the standard and trial plates and an arerage taken of the reciprocals for each plate. The ratios of these averages are the values given in the first column for each metal. A decrease in the number therefore means less radiation, and an increase, a greater radiation from the trial plate.

If the coil or tube worked irregularly while any one set of readings was taken, the values for the standard plate did not agree, and such a set could then be discarded. Fortunately this happened very seldom. Variations in the tube between two sets of readings did not affect the character of the change taking place in the trial plate, although they would alter the absolute value of the per-cent. change.

TABLe I.

Unpolished Metal Plates in Air.

\begin{tabular}{|c|c|c|c|c|c|c|}
\hline Exposure. & $\begin{array}{c}\text { Iros. } \\
\text { Ratio to } \\
\text { Standard } \\
\text { Plate. }\end{array}$ & $\begin{array}{l}\text { IJEAD. } \\
\text { Ratio. }\end{array}$ & $\begin{array}{c}\text { Nickel. } \\
\text { Ratio. }\end{array}$ & $\begin{array}{l}\text { Zinc. } \\
\text { Ratio. }\end{array}$ & $\begin{array}{c}\text { Copper. } \\
\text { Ratio. }\end{array}$ & $\begin{array}{c}\text { ALuminivM. } \\
\text { Ratio. }\end{array}$ \\
\hline 0 hours ...... & 100 & 100 & 100 & 100 & 100 & 100 \\
\hline $1 \quad,, \quad \ldots \ldots$ & 91 & $\ldots$ & 97 & 97 & 100 & 99 \\
\hline $2, \ldots \ldots$ & $\ldots$ & 93 & 95 & 94 & 90 & 96 \\
\hline $3 \quad, \quad \ldots \ldots$ & 90 & 94 & 92 & 91 & 98 & 98 \\
\hline $4 \quad, \quad \ldots \ldots$ & $\ldots$ & 95 & $\cdots$ & $\ldots$ & $\ldots$ & ... \\
\hline $5 \quad, \quad \ldots \ldots$ & $\cdots$ & $\ldots$ & ... & $\ldots$ & .. & $\ldots$ \\
\hline $6 \quad, \quad \ldots . .$. & $\cdots$ & 94 & ... & $\cdots$ & $\cdots$ & $\ldots$ \\
\hline Rest .......... & $\ldots$ & $\cdots$ & $\ldots$ & $\ldots$ & ... & $\cdots$ \\
\hline $30 \mathrm{~min} . . . . .$. & 100 & $\ldots$ & $\ldots$ & 94 & 98 & ... \\
\hline $45,, \ldots \ldots$ & $\ldots$ & 100 & $\ldots$ & .. & ... & ... \\
\hline 18 hours $\ldots$ & $\cdots$ & $\ldots$ & 97 & 99 & $\cdots$ & $\cdots$ \\
\hline
\end{tabular}

The examples chosen are characteristic of the different metals when the surface has been allowed to age in air for some months, and they are not at all exceptional in uniformity of the readings. They show, with the possible exception of copper and aluminium, a decided falling-off in the power of giving off secondary radiation. This fatigue is, however, a 
temporary effect, as the plates recover their original activity if the Röntgen rays are stopped for a time. Iron and lead required a rest of less than an hour, but the effect on nickel and zinc was more lasting, as they still showed some fatigue after resting until the following day.

\section{Polished Metal Plates in Air.}

The same plates were then polished with emery and with silk to a mirror surface and tested as soon as possible, allowing only time enough, before taking the first set of readings, for the plates to lose the heat which might have been developed by the friction. This delay, I think, is important, since if the fatigue is at all dependent on surface-films of gas and gas occluded in the metal, these would be strongly affected by changes of temperature.

\section{TABLE II.}

\begin{tabular}{|c|c|c|c|c|}
\hline Exposure. & $\begin{array}{c}\text { Inon }_{1} . \\
\text { Ratio to } \\
\text { Standard } \\
\text { Plate. }\end{array}$ & $\begin{array}{l}\text { IroN }_{2} . \\
\text { Ratio. }\end{array}$ & $\begin{array}{l}\text { LEAD. } \\
\text { Ratio. }\end{array}$ & $\begin{array}{l}\text { Nickel. } \\
\text { Ratio. }\end{array}$ \\
\hline 0 hours .... & 100 & 100 & 100 & 100 \\
\hline $1, \ldots$ & 105 & 106 & 103 & 98 \\
\hline $2 \quad, \ldots$ & 103 & 108 & 105 & 101 \\
\hline $3 \quad, \quad \ldots$ & 102 & 109 & 101 & 98 \\
\hline$n \quad \ldots$. & $\ldots$ & 109 & 101 & $\cdots$ \\
\hline
\end{tabular}

The effect of the Röntgen rays is here just the reverse, as the secondary radiation for iron and lead rises to a maximum. Unfortunately, the experiments could not be continued long enough to see whether the ratios finally became less than the initial value. While nickel does not show this increase in radiation, it remains practically unaffected and does not fatigue as it did before the surface was polished.

In the following experiments the trial plates were immersed in gases, at atmospheric pressure, other than air.

\section{Polished Plates in Coal-gas.}

Both the trial and standard plates were well polished and placed in their respective boxes. The windows of both were closed with aluminium-foil free from holes, and the box containing the trial plate was sealed air-tight with wax. A slow 
stream of coal-gas was then passed through it for at least a day and allowed to stand over night and started again. The gas entered by the lower tube, $\vec{C}$, and issued from the higher level. During the test a very slow stream of the gas flowed through this box, as it seemed to be the best method of keeping the atmosphere uniform and pure, as occluded gas issuing from parts of the box would be removed.

TABLe III.

\begin{tabular}{|c|c|c|}
\hline Exposure. & $\begin{array}{c}\text { Iron. } \\
\text { Ratio to } \\
\text { Standard Plate. }\end{array}$ & $\begin{array}{l}\text { Nicket. } \\
\text { Ratio. }\end{array}$ \\
\hline 0 bours ................ & 100 & 100 \\
\hline $1, \quad, \quad \ldots \ldots \ldots . .$. & ... & ... \\
\hline $2 \quad, \quad \ldots \ldots \ldots \ldots$ & 105 & 98 \\
\hline $3 \quad, \quad \ldots \ldots \ldots .$. & 106 & 99 \\
\hline $4 \quad, \quad \ldots \ldots \ldots \ldots$ & 104 & 98 \\
\hline $5, \quad, \quad \ldots \ldots \ldots .$. & $\cdots$ & $\cdots$ \\
\hline ............ & 105 & $\ldots$ \\
\hline
\end{tabular}

These results are similar in character to those for polished surfaces in air.

\section{Polished Plates in Hydrogen.}

The effect of immersing the plate in hydrogen was tried with iron, as this metal gives apparently the most characteristic results. The hydrogen was generated from pure zinc and sulphuric acid and passed through drying-tubes before entering the test-box. Considerable difficulty was experienced in getting rid of traces of air. The gas passed through the box for four hours in a slow stream, entering near the top and issuing from the bottom, and the plate was then allowed to stand all night in the atmosphere of hydrogen. In the morning, the stream of gas was again sent through the box continuously until two o'elock when a test was made. During the test also the stream, reduced in quantity, continued to flow.

It is essential for good results to drive out all traces of air from the trial plate and to keep the standard plate in air. These precautions are necessary because the ionization currents produced in hydrogen and air by the same secondary radiation are not at all equal. So, for example, we might suppose a 
constant secondary radiation to be set up by the trial plate in hydrogen, and at the same time the quantity of air remaining in the box to change slightly and slowly. Then we should have all the appearance of a change in this constant secondary radiation. Or, if the quantity of air changed quickly, we should naturally attribute the consequent change in the ionization current to irregalarity in the working of the Röntgenray bulb. But if we keep the standard plate in air, the latter error would be correctly interpreted by the constancy of the readings of its ionization current. The former difficulty cannot be certainly prevented. The best I could do was to make it strongly probable that slow changes in the gas did not occur. This was done by taking a set of readings for both the standard and the trial plates. Immediately afterwards, the lead shutters on both boxes were closed and remained so for half an hour. If another set of readings for both plates were then taken, the ratio should be the same as before. Previous to beginning a test for fatigue, this process was repeated two or three times at half-hour intervals, or until the ratios did remain constant within the limit of accuracy of reading. In some cases it was necessary to continue the flow of gas for two or three days before a steady state was reached.

TABLe IV.

\begin{tabular}{|c|c|c|}
\hline Exposure. & $\begin{array}{c}\text { Iros }_{1} \\
\text { Ratio to } \\
\text { Standard Plate. }\end{array}$ & $\begin{array}{l}\text { IRON }_{3} . \\
\text { Ratio. }\end{array}$ \\
\hline 0 hours ... & 100 & 100 \\
\hline $1, \quad \ldots \ldots$ & 94 & 103 \\
\hline $2 \quad, \quad \ldots$ & 95 & 100 \\
\hline $3 \quad, \quad \ldots$ & 93 & 101 \\
\hline
\end{tabular}

The behaviour of the two samples of iron is different, as the first shows a slight fatigue and the second a small increase in activity. But I am led to believe that the effect of the hydrogen is practically to prevent change in the activity. The separate readings of the ionizations in the trial box, in spite of great care, were not so accurate as in the other experiments. And this was to be expected for the reasons given above. Even if the preliminary experiments remained constant and indicated that all the air was expelled, yet it is very possible that long continued use of the Röntgen rays may 
affect surface-films of air or assist in liberating air occluded in the metal. This opinion is supported by the fact that in neither case was there a regularly increasing change with the time. The first reading for $\operatorname{Iron}_{1}$ and the second value for Iron $_{2}$ are the only ones which show a decided change.

\section{Effect of Ozone on Polished Plates.}

Hallwachs* finds in his experiments on photo-electric fatigue that ozone in small quantities has an extraordinarily large influence. For example, a copper plate had its sensibility to these rays diminished as much in seven seconds when 0.01 of one per cent. of ozone was added to the air as would occur in a year if the ozone were absent from the air. We should expect that ozone would have also a comparatively large effect on the activity produced by the Röntgen rays. But no abnormally large effect could be found.

Ozone was generated by sparking between two coaxial cylinders, and air mixed with the ozone was sucked through the box by means of a water-pump. For fear the ozone might dissociate if allowed to stand, the stream of ozonized air was maintained during the entire experiment. A test for ozone was made every hour on the air issuing from the box, by passing it through a solution of potassium iodide and starch, and a strong reaction occurred each time. When the experiment was completed, the air in the box also smelled strongly of the ozone.

The first readings were taken with both plates in pure air. Fifteen minutes later the ozone was added to the air surrounding the test-plate.

TABLE V.

\begin{tabular}{|c|c|c|}
\hline Esposure. & $\begin{array}{c}\text { Iron. } \\
\text { Ratio to } \\
\text { Standard Plate. }\end{array}$ & $\begin{array}{c}\text { Copper. } \\
\text { Ratio. }\end{array}$ \\
\hline 0 hour. & 100 & 100 \\
\hline$\frac{1}{2} \quad, \quad \ldots \ldots . .$. & 97 & 95 \\
\hline $1 \%$ & 97 & 97 \\
\hline 2 hours .......... & 97 & 96 \\
\hline 3 & 98 & $\ldots$ \\
\hline
\end{tabular}

* Hallwachs, loc. cit. p. 381. 
A comparison of these results with those for the same plates in pure air, shows that the presence of ozone in small quantities does increase the fatigue. The difficulties explained when hydrogen was employed do not apply here, and the separate readings were quite accurate. Fresh surfaces of iron in air experienced an increase in activity, and copper showed little or no change, but on the addition of ozone there results for both a small fatigue. But evidently no such abnormal effects occur as Hallwachs found for ultra-violet light.

\section{Summary of Results.}

The preceding experiments prove that all the metals tried, with the possible exception of copper and aluminium, experience a fatigue when subjected to Röntgen radiation for a long period of time, if their surfaces are not polished. The greatest diminution in activity was found in iron and zinc, and amounted to about 10 per cent. for a three-hour exposure to the rays. The fatigue is not a permanent effect, as the plates recovered their original activity after a comparatively short rest.

When iron and lead are freshly polished, the secondary radiation increases and reaches a maximum value after an exposure of an hour or two; the behaviour of nickel is different, as there was no regular change in its radiation during an interval of three hours.

The effect of immersing polished plates in coal-gas, which would probably form sulphides on the surface, is not noticeably different from the action in air. An inert gas, like hydrogen, apparently tends to prevent changes in activity. Lastly, when ozone is added to the air surrounding polished iron and copper plates, a considerable fatigue occurs, but not comparable to the effect noted by Hallwachs.

The explanation of these results is decidedly in favour of the fatigue being caused by changes of the gas in or on the plates, rather than to any change in the metals themselves. It is impossible as yet to decide definitely whether this effect on the adjacentgas-films is caused by an increased or diminished power of absorption of the secondary rays, or whether it is due to the formation or destruction of electrified double-layers.

But the experiments indicate that a modification of an electrified double-layer by the rays is the more probable of the two. A metal whose surface has stood untouched for months, diminishes in its secondary radiation from the beginning of the bombardment by the Röntgen rays. Now we must suppose that what condensed gas or double-layers may have formed on the plate during the preceding months, will be in such a sufficiently. stable state as not to change appreciably 
of themselves during the three hours or so of the experiment. Consequently the fatigue must be due to a modification in these films by the Röntgen rays. We do know that the contact potential of the metal changes during exposure to ultra-violet light and, presumably also, to Röntgen rays, and this change of potential is best explained as a modification of an electritied double-layer which has formed on the surface ; but we have no evidence that the rays increase the density and absorbingpower of condensed gas-films. The fact that freshly polished plates increased in radiating power for an hour or so, points even more strongly to the above conclusion. The effect of polishing is undoubtedly to remove, at least partially, such double-layers and gas-films. During the first part of the experiment the films are forming and the radiation increases. The formation of an electrified double-layer may easily have such an effect, but it is extremely difficult to see how the absorptive power of a gas can diminish while it itself is growing denser. After the maximum value is reached and the radiation begins to decrease, we have the same conditions. discussed above.

As these experiments are the first attempt to show the fatigue of metals due to Röntgen rays, they can be compared only to the similar action of ultra-violet light. Of the investigators of the latter effect, Lenard ascribes it to the formation of electrified double-layers, and Buisson to an absorption of the rays by occluded gas. Hallwachs, who finds these insufficient to account for all the phenomena, assigns the dominant action to an abnormal absorptive power of ozone existing as a thin film close to the metallic surface. He claims that even so minute a quantity as $1 / 130,000$ of one per cent. of ozone in the air would fully account for the normal fatigue.

In a general way, my results agree with these views. And in particular I have observed at times an increased sensibility to the radiation corresponding to what Hallwachs found for certain freshly prepared plates previonsly kept in closed vessels for a considerable time. It is rather surprising there should be such an agreement. The ultra-violet radiation consists entirely of easily absorbed rays, while the secondary radiation excited by Röntgen rays contains not only cathode rays but also a proportion of penetrating rays. The presence of these latter tends to complicate the results, as they would not be absorbed easily by surface-films of gas. Since Sagnac* found that the secondary radiation emitted by a light substance, such as aluminium, contains a large proportion of penetrating rays, we should expect its radiation to be the most unvarying

* Sagnac, Ann. de Chim. et de Phys. xxii. p. 493 (1901). 
if the fatigue were due to absorption by gas. Also the presence of these penetrating rays may be one reason why ozone has a less influence.

'The other theory advanced to explain the phenomena is that a change occurs in the metal itself. Ladenburg suggested chemical corrosion of the surface to be the cause, but the recent work of Hallwachs makes this hypothesis doubtful. Then we have the theories of Allen and of Ramsay and Spencer, that the radiation of metals is due to an actual disintegration of the substance. In some way, the ultra-violet light releases the atomic energy and causes the atom to explode. So if we begin with zinc (A) we soon get a disintegration product zinc (B), then zinc (C), \&c. It is rather unfortunate that so fundamental an assumption as the transmutation of the elements should be advanced except as a last resort and with very convincing proofs. And certainly in the present case such proof is lacking. In the first place, the fatigue is not a permanent change and metals recover their primitive efficiency. Then, too, Allen finds that the change from zine (A) to zine (B) occurs in a few minutes. If such a change takes place so quickly, we should expect to find some evidence of this new product on the surface of metals which have heen exposed to sunlight for years. But the facts discovered by him, that the fatigue progresses rapidly at first and then at a slower rate and that the action may be expressed as the sum of two exponentials, are important and interesting. But a less radical assumption would satisfy his exponential equation.

Ramsay and Spencer go much further. They suppose the ultra-violet light to produce a disintegration of the atom accompanied by the ejection of a corpuscle, and that this process is repeated until the number of corpuscles emitted is equal to the valence of the element. The proof of this circumstantial disintegration rests solely on the fact that their curves of radiation and time show breaks, or all their measurements do not lie on a smooth curve. When we consider the difficulty of keeping a source of ultra-violet iight constant for hours at a time and the errors liable to occur when measuring the radiations from the plates, it is not surprising there are irregularities in the curves. An inspection of thein does not carry conviction that successive disintegrations of matter under normal couditions are involved. Nor do the authors prove any extraordinary precautions to prevent errors were taken. In fact they do not explain why other points which lie at some considerable distance from the curves drawn (see particularly curves III. and IV., plate vi., and curve VIII., plate vii.) do not constitute points of disintegration. After the exhaustive and rigorous treatment of the subject 
by Hallwachs, in addition to the work of his predecessors, there seems little doubt that the simpler idea of changes in the absorptive power of electrified double-layers and other films of gases of great density near the surface of the metals, is the probable cause of fatigue. And the experiments described in this paper show no reason for not accepting the same hypothesis to explain the changes occurring in this type of secondary radiation.

I take great pleasure in thanking Professor Thomson for his advice and for his many courtesies to me during my visit to the Cavendish Laboratory.

Cavendish Laboratory, Cambridge, March 1907.

LXIII. The Action of Uniform Electric and Magnetic Fields on. Moving Electrons. By A. H. Bucherer, D.Sc., Bonn University*.

N my paper on a new principle of relativity in electro1 magnetism (Phil. Mag., April), in which I have calculated the forces acting on moving electrons in the uniform fields of electromagnets and of condensers, I have omitted to call special attention to the circumstance that the expressions obtained do not apply to all kinds of uniform fields. In fact, as will be evident at once from the reasoning adopted by me, l.c., the forces on the electrons primarily depend on the distribution of electric and magnetic masses, and indirectly only on the intensities of the fields in which they are moving. Thus electrons moving in various uniform fields of the same intensity will in general experience different forces if these fields are due to different distributions of electric and magnetic masses, special care being requisite with solenoids which must be replaced by equivalent magnetic shells.

Closely connected with this is another important consequence. Let an electron move in the uniform superimposed fields $\mathbf{H}_{0}{ }^{\prime}$ and $\mathbf{H}_{0}^{\prime \prime}$ of two electromagnets. Then, to find the resultant force, it is not permissible to substitute the resultant field $\mathbf{H}_{0}^{\prime \prime \prime}$ in the expression given by me. For evidently $\frac{\mathrm{VH}_{0}{ }^{\prime} \mathbf{u}}{1-\frac{u^{2}}{v^{2}} \cos ^{2}\left(\mathbf{H}_{0}{ }^{\prime} \mathbf{u}\right)}+\frac{\mathrm{VH}_{0}{ }^{\prime \prime} \mathbf{u}}{1-\frac{u^{2}}{v^{2}} \cos ^{2}\left(\mathbf{H}_{0}{ }^{\prime \prime} \mathbf{u}\right)} \neq \frac{\mathrm{VH}_{0}{ }^{\prime \prime} \mathbf{u}}{1-\frac{u^{2}}{v^{2}} \cos ^{2}\left(\mathbf{H}_{0}{ }^{\prime \prime} \mathbf{u}\right)}$.

I am preparing experiments with Becquerel rays in order to test the formulæ derived by me from the principle of relativity.

Bonn University, April 1907.

* Communicated by the Author.

Phil. Mag. S. 6. Vol. 13. No. 78. June 1907. 